\title{
Developing Virtual Reality Module to Improve Student Learning Experience in Additive Manufacturing Curriculum
}

\section{Prof. Jing Zhang, Indiana University Purdue University, Indianapolis}

Dr. Jing Zhang's research interests are broadly centered on understanding the processing-structureproperty relationships in advanced ceramics and metals for optimal performance in application, and identifying desirable processing routes for its manufacture. To this end, the research group employs a blend of experimental, theoretical, and numerical approaches, focusing on several areas, including:

1. Processing-Microstructure-Property-Performance Relationships: thermal barrier coating, solid oxide fuel cell, hydrogen transport membrane, lithium-ion battery 2. Physics-based Multi-scale Models: ab initio, molecular dynamics (MD), discrete element models (DEM), finite element models (FEM) 3. Coupled Phenomena: diffusion-thermomechanical properties 4. Additve Manufacturing (AM) or 3D Printing: AM materials characterization, AM process (laser metal powder bed fusion, ceramic slurry extrusion) design and modeling

(http://www.engr.iupui.edu/ jzz29/)

\section{Mr. Glorio Singui, \\ Mr. Shambhuraj Hansraj Wadghule \\ Mr. Chauncey Eugene Frend \\ Mr. Tejesh Charles Dube, Indiana University Purdue University, Indianapolis}

Tejesh Charles Dube is a mechanical engineering graduate student interested in structural and material science applications. His research interests revolve around CAD modeling, additive manufacturing, design for sustainable manufacturing and bioengineering.

\section{Mr. Michael Golub, IUPUI}

Michael Golub is the Academic Laboratory Supervisor for the Mechanical Engineering department at IUPUI. He is an associate faculty at the same school, and has taught at several other colleges. He has conducted research related to Arctic Electric Vehicles and 3D printed plastics and metals. He participated and advised several student academic competition teams for several years. His team won 1st place in the 2012 SAE Clean Snowmobile Challenge. He has two masters degrees: one M.S. in Mechanical Engineering and an M.F.A. in Television Production. He also has three B.S. degrees in Liberal Arts, Mechanical Engineering, and Sustainable Energy. 


\title{
Developing Virtual Reality Module to Improve Student Learning Experience in Additive Manufacturing Curriculum
}

\author{
Jing Zhang, Glorio Singui, Shambhuraj Hansraj Wadghule, Chauncey Frend, Tejesh Charles \\ Dube, Michael Golub \\ Indiana University - Purdue University Indianapolis, Indianapolis, Indiana, USA
}

\begin{abstract}
In our current additive manufacturing (AM) curriculum, the study relies on taking lectures and physical lab experiments. With the advance of virtual reality (VR) technologies in terms of both software and hardware, there is a need to advance the education with adopting advanced VR technologies. In this project, we present our latest results of developing new VR modules in AM curriculum. Specifically, the developed VR modules for fusion deposition modeling and fatigue testing will be presented. In the on-going research, students will be required to use the VR modules in comparison with the physical lab experiments. The focus will be understanding the effectiveness of VR technology on engineering curriculum.
\end{abstract}

\section{Introduction}

At Indiana University - Purdue University Indianapolis (IUPUI), a strong focus on providing education and research opportunity for workforce development has led to multiple projects and initiatives. Through the support from the IUPUI STEM Education Innovation and Research Institute (SEIRI) and Multidisciplinary Undergraduate Research Institute (MURI), a team of students and faculty are working together to develop virtual reality (VR) modules with the aim of improving student learning experience in additive manufacturing (AM) curriculum. The overarching goal of the project is to adopt VR technique to improve the learning outcomes and student engagement of studying of additive manufacturing in an active learning environment.

As shown in the literature review in Section 2, the study of adopting VR in AM education is still largely missing. This is probably due to a knowledge gap of developing VR modules for most engineering researchers. If successful, this study will help to fill the gap and promote VR technique in engineering and other STEM education.

To address the issue brought up by the knowledge gap, in this project, we propose to use a betweensubjects experimental design approach. In this approach, selected student participants will be randomly assigned to three conditional groups. The conditions include (i) a VR simulation only group that tasks the users with learning an AM process (e.g., Fused Deposition Modeling, or FDM) or materials testing (e.g., tensile or fatigue testing of additively manufactured samples) in a manufacturing environment, (ii) a conventional hands-on lab group where students do actual FDM or tensile testing, and (iii) a group of using both the VR and hands-on experiments. Each experimental condition begins with an orientation training session designed to teach students about VR and AM techniques. 


\section{Literature review}

On February 11, 2019, President Donald Trump signed an executive order launching the American Artificial Intelligence (AI) Initiative, directing federal agencies to focus on the technology. AI has become a defining issue, affecting national security, economic development, human rights, and social media. Currently, VR for AI has been studied in the form of human-centered simulation for social science [1], and researchers have applied AI to VR, which is called Intelligent Virtual Environments [2]. It is expected that VR and/or combined AI will have significant increase of funding opportunities from the federal governments.

VR has the potential to improve learning outcomes and student engagement in an active learning environment. VR is the use of three dimensional (3D) computer graphics in combination with interface devices to create an interactive, immersive environment[3]. Due to improvements in technology and reductions in cost, the use of VR in education has increased greatly over the past ten years [4], [5]. Emerging consumer VR devices are starting to provide sufficient quality and affordability for home and school use, and this will eventually make educational VR experiences broadly available. Future consumer VR headsets are expected to include increased sensing, such as eye tracking cameras to determine where users are looking and strain gauges to detect facial expressions. The sensor data can be analyzed for insight into users' attention and emotional effect. $\mathrm{VR}$, and technology in general, is believed to facilitate learning through engagement, immersion and interactivity [6]. Technology is also lauded for its ability to provide a more customized learning experience that can be accessed at the learner's convenience [7]. Of the educational technologies currently being utilized, VR is viewed as promising because of its unique ability to immerse learners in environments they are studying, such as in ancient cities, manufacturing environments, or a look into the human body. Research into the effectiveness of technology based educational tools, including VR, has demonstrated tangible benefits, such as reduced learning time and better learning outcomes [5], [8]. Technologies such as VR have also greatly expanded both access to educational opportunities as well as a range of programs that could be offered in an online setting [9].

\section{Method}

\subsection{Assessment and evaluation plan}

Learning outcomes and perceived engagement, usability, and satisfaction will be measured via assessment tests and surveys. The assessment methods include both formative and summative assessments, post-test, post-survey about virtual reality simulations and hands-on lab experiments. Pre-test and Pre-survey will be used. The pre-test includes multiple choice questions covering key objectives throughout the primary module content. The pre-survey includes technical questions and basic demographic questions including GPA and number of Internet courses taken and questions designed to better understand student self-efficacy toward computer and VR use. The assessment and evaluation methods based on the objectives are summarized in Table 1 below. 
Table 1: Summary of assessment \& evaluation methods and of their effectiveness

\begin{tabular}{|c|c|c|}
\hline Objectives & $\begin{array}{l}\text { Assessment and evaluation } \\
\text { methods }\end{array}$ & $\begin{array}{l}\text { Indication of effectiveness of } \\
\text { the assessment/evaluation }\end{array}$ \\
\hline $\begin{array}{l}\text { 1. Development of a series of } \\
\text { VR modules for AM process, } \\
\text { and materials testing; }\end{array}$ & $\begin{array}{l}\text { Monthly collaborative } \\
\text { meetings of the PI and key } \\
\text { personnel. }\end{array}$ & $\begin{array}{l}\text { Functioning VR modules; } \\
\text { YouTube video demos. }\end{array}$ \\
\hline $\begin{array}{l}\text { 2. Conducting studies to } \\
\text { compare the effectiveness of } \\
\text { VR experiences versus } \\
\text { conventional hands-on } \\
\text { laboratory experiences; }\end{array}$ & $\begin{array}{l}\text { IRB approved assessment of } \\
\text { using the VR modules in } \\
\text { different groups in selected } \\
\text { classes. }\end{array}$ & $\begin{array}{l}\text { IRB approval, and conducting } \\
\text { of the comparative study. }\end{array}$ \\
\hline $\begin{array}{l}\text { 3. Assessment of the } \\
\text { effectiveness of the VR } \\
\text { technique in } 100+ \\
\text { students/year who are taking } \\
\text { AM relevant courses; }\end{array}$ & $\begin{array}{l}\text { Using students' pre and post } \\
\text { tests and survey in three } \\
\text { different groups - VR only, } \\
\text { conventional only, and } \\
\text { combined VR+ conventional } \\
\text { groups. }\end{array}$ & $\begin{array}{l}\text { Students' outcomes and class } \\
\text { survey data results showing } \\
\text { comments of using VR } \\
\text { modules in learning. } \\
\text { Modification of the existing } \\
\text { AM courses to add VR } \\
\text { modules. }\end{array}$ \\
\hline $\begin{array}{l}\text { 4. Disseminating of the } \\
\text { knowledge obtained from the } \\
\text { studies in the School of } \\
\text { Engineering and Technology, } \\
\text { across the IUPUI campus, and } \\
\text { in national or international } \\
\text { conferences. }\end{array}$ & $\begin{array}{l}\text { Making presentations and } \\
\text { publications. } \\
\text { Key personnel Juarez's thesis } \\
\text { research. }\end{array}$ & $\begin{array}{l}\text { List of presentations and } \\
\text { publications. }\end{array}$ \\
\hline
\end{tabular}

\subsection{VR modules development}

Two VR modules are under development [10]. The first one is the fused deposition modeling (FDM) process. As mentioned previously, the research reported in here aims to provide users with a medium to learn, get familiar, and interact with the additive manufacturing process. To achieve this goal, we proceeded step by step towards developing the virtual reality module that replicates a real 3D printer, namely the MakerBot Replica Mini as shown in Figure 1. This was done using a suite of 3D modeling software. In all, we parted the research into two sections. In section one, we designed a 3D printer using the MakerBot as the reference and in the other section, we proceeded with simulating the $3 \mathrm{D}$ printing process and implementing the virtual reality aspects to the 3D model. The CAD model of the MakerBot Replicator Mini was created in PTC Creo software where all the assembly and mechanism aspects were also integrated into the model, as shown in Figure 2. And to start simulating the motion of the printer, we switched to Autodesk 3ds Max, and we completed the mechanism of the printer and assigned motion controls to individual 
parts of the model to perform specific movements. The CAD file when imported in the AutoCad 3Ds Max software had to be modified in many ways.

To approximate the printed model to real models, we set the velocity scale to be 2 generic units, and the viscosity of the extruded fluid to be $7,000 \mathrm{mPa}$.s. Usually, in a real printer, these parameters are defined using a slicing software which can handle simple and complex parts and predefine their layer-by-layer deposition. However, in our application, we used a path constraint animation to replicate the work of a slicing software. This allowed us to constrain the $\mathrm{X}$ and $\mathrm{Y}$ motion of the extruder to a predefined path in order to generate the layer-by-layer deposition.

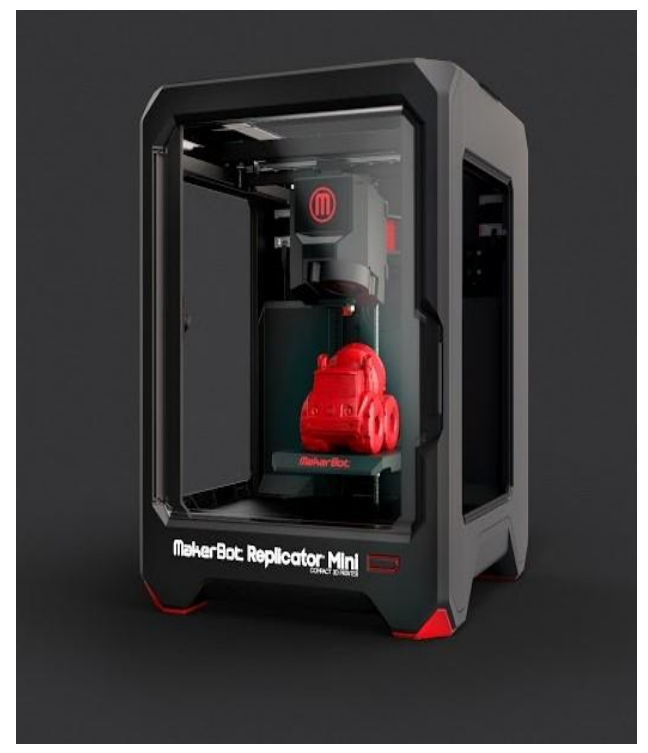

Figure 1. MakerBot Replica Mini

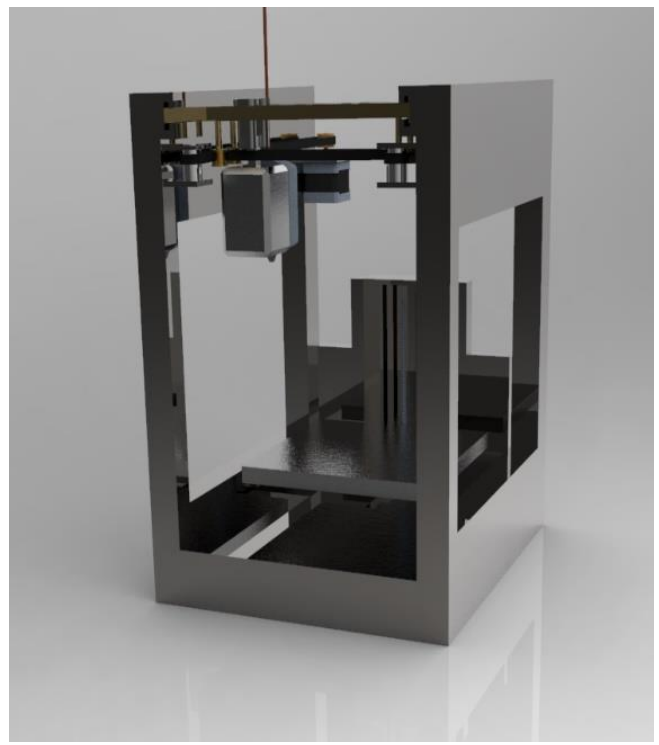

Figure 2. CREO model developed in the project for the 3D printer 
We used the previous development to modify the simulation using advanced software Unity. Unity, being an advanced real-time development platform, has the capabilities to integrate virtual reality aspects to the model. The aim is to create a virtual environment in which we can have the $3 \mathrm{D}$ printer with some interactive features allowing the user to observe how different parameters can affect the $3 \mathrm{D}$ printing process. For example, the user can alter parameters such as the speed of the 3D printing, the viscosity of the material, and even choose a different geometry to print.

The second VR module is fatigue testing, done by a student who collaborated with the team. In this VR module, the fatigue testing, microstructure analysis of the broken samples are demonstrated (see Figure 6).

In this study, selected student participants will be randomly assigned to three conditional groups. The conditions include (i) a VR simulation only group that tasks the users with learning an AM process (e.g., Fused Deposition Modeling, or FDM) or materials testing (e.g., tensile or fatigue testing of additively manufactured samples) in a manufacturing environment, (ii) a conventional hands-on lab group where students do actual FDM or tensile testing, and (iii) a group of using both the VR and hands-on experiments. Each experimental condition begins with an orientation training session designed to teach students about VR and AM techniques.

\section{Preliminary results and discussion}

After replicating the 3D printer MakerBot Replicator Mini in the software PTC Creo and adding a mechanism part to it, it was imported to the AutoCad 3Ds Max software with a few variations in the properties such as the scale of the 3D printer and hierarchy of the different components of the printer. The software 3Ds Max allowed to add advanced mechanisms to the printer so the individual components can perform the desired motion.

To accurately represent the $3 \mathrm{D}$ printing process in the simulation in the provided time frame of the software, many physical properties were changed achieving the simulation of the two layered hollow cylinder. As shown in Figures 3, 4 and 5, the extrusion process involved the use of the fluid 'toothpaste' in the software. 


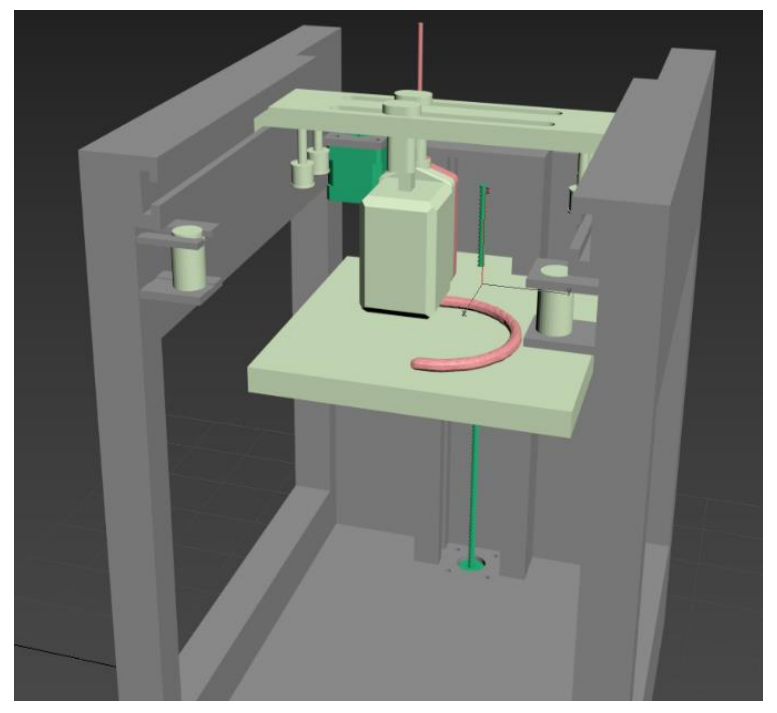

Figure 3. First layer deposition.

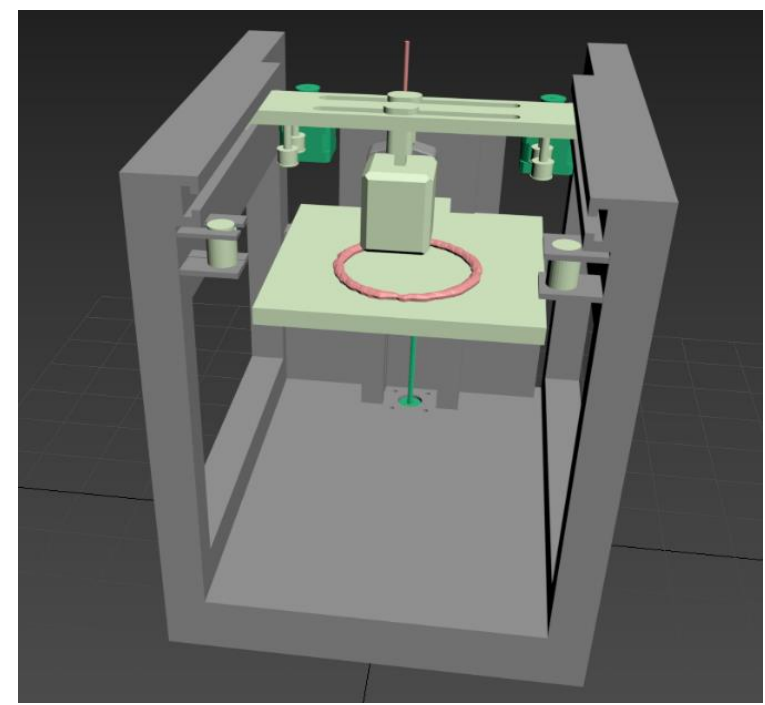

Figure 4. Layer deposition completion of the first layer. 


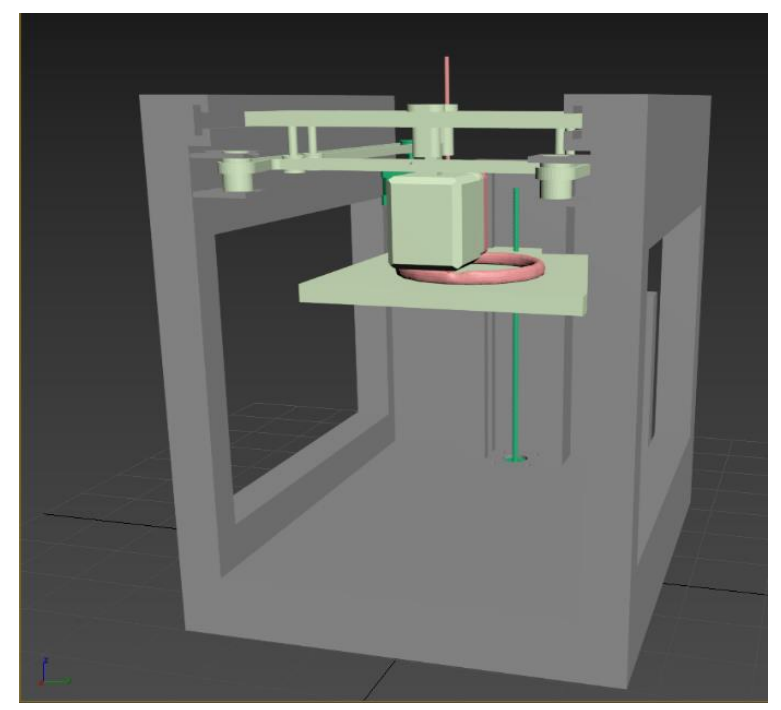

Figure 5. Second layer deposition

For the fatigue testing VR module, as shown in Figure 6, it is fully functional now. As a demonstration, the student who developed the module has a YouTube video to show the functionalities of module.

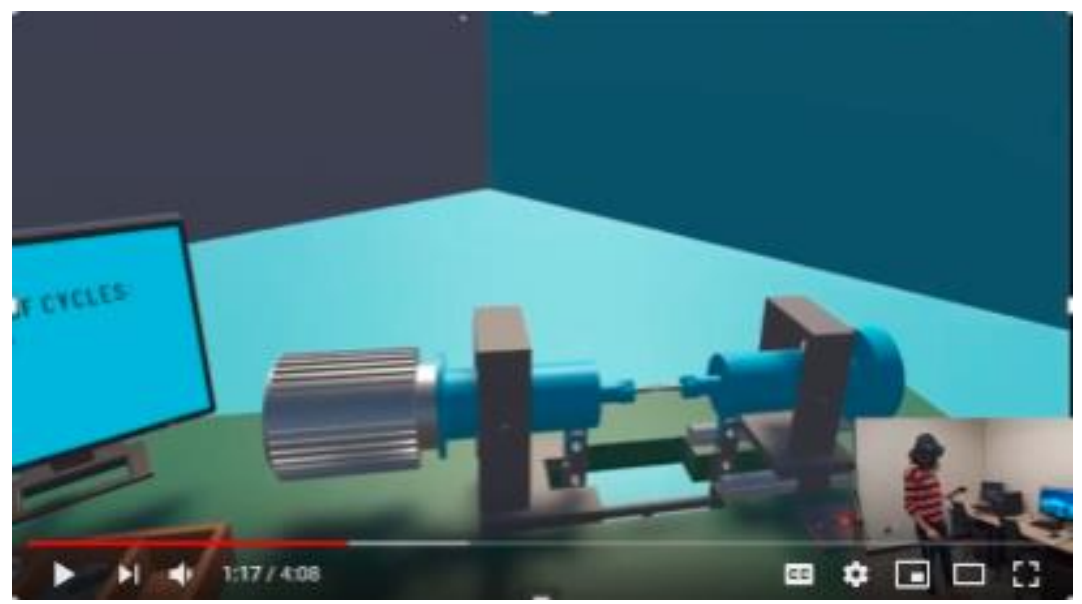

Figure 6. The fatigue testing VR module (the student is shown in the bottom right of the screen). (The complete VR demo is available at YouTube website: https://www.youtube.com/watch?v=Up4cBJhfcco )

\section{Summary}

In this work, we present our preliminary results about building VR modules for additive manufacturing curriculum. Two VR modules for fusion deposition modeling and fatigue testing are presented. In the on-going research, students will be required to use the VR modules in comparison with the actual physical lab experiment, thus the effectiveness of the using VR will be assessed. 


\section{Acknowledgments}

The authors acknowledge the support from the IUPUI STEM Education Innovation and Research Institute (SEIRI) and Multidisciplinary Undergraduate Research Institute (MURI). The fatigue testing VR module developed by Cynthia Juarez is also acknowledged.

\section{References}

[1] P. Cipresso and G. Riva, "Virtual Reality for Artificial Intelligence: human-centered simulation for social science," in Studies in Health Technology and Informatics, ed: IOS Press, 2015.

[2] R. Aylett, M. Luck, M. Wt Coventry, and C. Al, Applying Artificial Intelligence to Virtual Reality: Intelligent Virtual Environments vol. 14, 2001.

[3] Z. Pan, A. D. Cheok, H. Yang, J. Zhu, and J. Shi, "Virtual reality and mixed reality for virtual learning environments," Computers \& Graphics, vol. 30, pp. 20-28, 2006/02/01/ 2006.

[4] R. Manseur, "Virtual reality in science and engineering education," in Proceedings Frontiers in Education 35th Annual Conference, 2005, pp. F2E-8.

[5] E. A.-L. Lee and K. W. Wong, "Learning with desktop virtual reality," Comput. Educ., vol. 79, pp. 49-58, 2014.

[6] Z. Merchant, E. T. Goetz, L. Cifuentes, W. Keeney-Kennicutt, and T. J. Davis, "Effectiveness of virtual reality-based instruction on students' learning outcomes in K-12 and higher education: A meta-analysis," Computers \& Education, vol. 70, pp. 29-40, 2014/01/01/ 2014.

[7] V.S Pantelidis, Reasons to Use Virtual Reality in Education and Training Courses and a Model to Determine When to Use Virtual Reality vol. 2, 2009.

[8] R. J. Stone, Haptic feedback: A brief history from telepresence to virtual reality, 2001.

[9] K. C. Madathil, K. Frady, R. Hartley, J. Bertrand, M. Alfred, and A. Gramopadhye, "An Empirical Study Investigating the. Effectiveness of Integrating Virtual Reality- based Case Studies into an Online. Asynchronous Learning Environment," Computers in Education Journal, vol. 8, pp. 1 - 7, 2017.

[10] J. Zhang, G. Singui, S. Wadghule, and C. Frend, "Virtual Reality Module for Additive Manufacturing Curriculum," in 2020 Illinois-Indiana Section Conference Proceedings, Indianapolis, Indiana, USA, 2020, pp. S900-1. 